\title{
La hermenéutica crítica de Habermas: una «profundización» de la hermenéutica gadameriana
}

\author{
Habermas's critical hermeneutics: \\ «Delving into» Gadamerian hermeneutics
}

\author{
MIKEL ARTETA \\ Universidad de Valencia
}

Recibido:26/04/14 Aceptado: 23/06/15

\section{RESUMEN}

En este artículo queremos analizar brevemente los rasgos principales de la hermenéutica filosófica de Gadamer, revelando la importancia pragmática de conceptos como arché, mythos o dihairesis. En la segunda parte, confrontaremos esta propuesta con las críticas que en su día le hizo Habermas, acompañando a Apel, para «profundizar» en la hermenéutica. Éste fue el punto de partida para fundamentar su conocida pragmática universal.

\section{PALABRAS CLAVE}

GADAMER, HERMENÉUTICA, CRÍTICA, HABERMAS, LENGUAJE

\section{ABSTRACT}

In this article we briefly examine the main features of Gadamer's philosophical hermeneutics, revealing the pragmatic importance of concepts like arché, mythos or dihairesis. In the second part, Gadamer's proposal will be confronted to Habermasian critique, in order to delve into hermeneutics. This was the starting point to support the latter's well-known «universal pragmatics».

KEYWORDS

HEIDEGGER, HERMENEUTIC CIRCLE, SCIENCE, PRE-UNDERSTANDING 


\section{INTRODUCCIÓN}

En SU OBRA Habermas SOSTIENE que en actitud performativa, la que tomamos al querer entendernos unos a otros, se da a todo hablante la posibilidad de emplear el «yo» del acto ilocucionario de modo que quede clara la pretensión de ser reconocido como persona individuada que asume de forma incanjeable su propia biografía (Kierkegaard). Además, como seres históricos y sociales que somos (Hegel), nos hallamos ya siempre en un mundo de la vida estructurado lingüísticamente (Humboldt). Y aunque el logos del lenguaje se sustrae a nuestro control para «abrirnos al mundo» y nos trasciende en las formas de comunicación en las que nos entendemos unos con otros acerca de algo en el mundo y acerca de nosotros mismos (Wittgenstein, Heidegger, Gadamer), lo cierto es que somos siempre nosotros, los sujetos capaces de hablar y actuar, quienes se entienden entre sí en este medio (Mead) (Habermas 1988a). En el contexto de la teoría crítica, conviniendo con K. O. Apel en que la comprensión hermenéutica «sólo puede servir al cercioramiento crítico de la verdad en la medida en que se suponga el principio crítico regulativo de llegar a un entendimiento universal en el marco de una ilimitada comunidad de interpretación» (Habermas 2007, p. 302), ${ }^{1}$ Habermas recuperará e integrará luego en su teoría de la acción comunicativa, sublimándolas, propuestas de muy distintos autores. Destacaremos aquí la apropiación que su teoría hizo, en un primer momento, de la hermenéutica gadameriana.

\section{LA HERMENÉUTICA FLOSÓFICA DE GADAMER}

Por hermenéutica normalmente comprendemos la «capacidad» que adquirimos en la medida en que aprendemos a dominar un lenguaje natural, y que podemos cultivar. Como tal, engloba tanto la capacidad de interpretación o arte de entender los sentidos lingüísticamente comunicables (contenidos semánticos del habla y los fijados por escrito) y de tornarlos comprensibles en caso de comunicaciones perturbadas, como la retórica o arte de la convicción y persuasión en situaciones en que ha de decidirse sobre cuestiones prácticas. A diferencia de la epistemología, que se ocupa de la relación entre lenguaje y realidad, la hermenéutica considera la lengua en funcionamiento, pragmáticamente, en la forma empleada por los participantes para alcanzar una comprensión conjunta; una comprensión que, aun prescindiendo de su conexión con la realidad objetiva (o precisamente gracias a ello), presupone la posibilidad de entendimiento universal. De ahí que no sea nada raro que varias propuestas ético-políticas universalistas o cosmopolitas beban directa y exclusivamente de las fuentes de la hermenéutica filosófica, con la que tratará 
de dar cuenta de la fuerza de los diálogos interculturales (Dallmayr 2001, pp. 252-263; Dallmayr 2006, pp. 3-14).

Frente al monopolio hegemónico del logos (explicativo, demostrativo, relacionado con la «ciencia» que descansa en la fundamentación y la prueba), que trajo la Ilustración griega remitiéndolo al ámbito racional de los números, Gadamer se propone recordar que al principio fue el mythos («proclamación», «dar a conocer una noticia») que, lejos de referirse a algo falso o inventado, se refería a «todo aquello que sólo puede ser narrado». El mythos no juega en el campo de lo verdadero y falsable, sino en el de la experiencia que trata de ser aprehendida y narrada, que aspira a ser «creíble»; sólo en ese sentido puede, por tanto, contener también algo de «verdad de lo universal» (Gadamer 1999, p. 25-27).

Gadamer se refiere al concepto de arché (con lo que se hace referencia tanto a la idea de «comienzo» como a la de «dominio») para responder a Weber que, si el conocimiento es una derivación a partir de principios, seguramente no podremos nunca fundar esos principios (politeísmo de los valores), pero tampoco debemos nunca dejar de retrotraernos a ellos, como nuevo comienzo. Se abraza, pues, la lógica de la inducción, más propia de la tópica que de la analítica; y esto dará pie a ver en el mythos el fundamento de la retórica aristotélica y, en consecuencia, de toda la filosofía hermenéutica (Gadamer 1999, p. 75 y ss.). Tras advertir la conversión del pensamiento en lenguaje, se devuelve a la retórica su campo de validez, dejando claro que «el proceso del entendimiento mutuo por medio de la dihairesis es un proceso rememorativo que avanza convenciendo al otro porque el otro rememora» (Gadamer 1999, p. 77).

Gadamer califica a la hermenéutica filosófica como una reflexión que pone ante la conciencia las experiencias que hacemos cuando usamos nuestra competencia comunicativa que, como ya hemos dicho, se desarrolla con la experiencia de la hermenéutica y de la retórica. La reflexión acerca de estos dos artes no está al servicio de una fijación de sus respectivas reglas sino de una meditación filosófica acerca de las estructuras de la comunicación en el lenguaje ordinario, a partir de las cuales Gadamer funda su teoría de la «fusión de horizontes». ${ }^{2}$

Al arte de entender y hacer comprensible, la hermenéutica filosófica debe las experiencias de una intersubjetividad ilimitada del entendimiento (cualquier plexo lingüístico es potencialmente comprensible, traducible, a plexos extraños de otros tiempos y lugares $){ }^{3}$ pero también la de su intersubjetividadSe

2 Para otro resumen de la hermenéutica filosófica: (Habermas 2010, p. 174)

3 «Existe una variedad inconmensurable de lenguas, pero en toda lengua es posible pensar. Se puede decir todo en cualquier lengua, si bien no siempre en una única frase o en una sola palabra. Para aquello que se quiere pensar se pueden buscar, y encontrar, las palabras. Eso es hablar» (Gadamer 1997, p. 223).. 
discontinua (debido a la diferencia de bagajes culturales nunca llegamos a entenderlo todo completamente, ${ }^{4}$ tanto en el seno de una misma comunidad de lenguaje socioculturalmente homogénea, como entre dos culturas o épocas distintas). $\mathrm{Al}$ arte de convencer y persuadir debe la hermenéutica filosófica la experiencia de que en el medio de la comunicación en el lenguaje ordinario, además de participarnos mutuamente cosas, también se forman y cambian actitudes orientadoras de la acción.

Por una parte, el poder de la retórica da cuenta de cómo el hablante, gracias a una gramática (sistema de reglas determinadas que permiten producir y entender un sinfín de oraciones) dispone de la creatividad del lenguaje natural para responder a los cambios de situaciones y definir nuevas situaciones mediante intervenciones lingüísticas en principio impredecibles. El «habla capaz», que genera un consenso acerca de cómo resolver una cuestión práctica, nos dice que es posible incluso cambiar los esquemas de interpretación en los que hemos crecido para poder enseñar a ver de otro modo lo tradicionalmente pre-entendido. En otras palabras, el sujeto que experiencia e interpreta se transforma para hacerse cargo de lo sucedido. Es lo que sucede cuando alguien que trata de entender un texto clásico se percata de que hay algo que no ha entendido; esa distorsión será el punto de partida para la inmersión del intérprete en el mundo del autor (en las realidades, valores y normas en las que creía, así como en sus vivencias) hasta transformarse y comprender por qué el autor hace ciertas afirmaciones en su texto (Habermas 2008a, p. 40). Habrá que tener muy en cuenta, no obstante, que la creatividad del sujeto, del autor clásico o de su intérprete, puede servir tanto para obnubilar como para ilustrar (Habermas 2007, p. 280 y s.). Esto es lo que preocupa a Habermas y que a Gadamer no parece importarle.

4 «En la multiplicidad del mundo de lenguas que ha ido creando la humanidad, toda lengua muestra también un raro distanciamiento y aislamiento. Al parecer, cada comunidad lingüística cuida con la puesta en práctica de la lengua su propia visión del mundo, aunque la 'lengua' de la lógica y del simbolismo matemáticos se corresponda con una necesidad general»Gadamer 1997, p. 223).. Sobre esto Habermas dice también lo siguiente: «la comprensión hermenéutica no puede penetrar libre de prejuicios (...), se ve atrapada por el contexto en que el sujeto que pretende entender ha empezado adquiriendo sus esquemas de interpretación. Esta precomprensión puede tematizarse, tiene que cotejarse con la cosa en todo análisis hermenéuticamente consciente. Pero incluso la modificación, en un caso dado, de esas anticipaciones inevitables no rompe la objetividad que el lenguaje cobra frente al sujeto hablante: las enseñanzas que obtenemos de esa modificación se articulan en una nueva precomprensión que a su vez nos sirve de guía en el siguiente paso hermenéutico»(Habermas 2007, p. 279). 
Pero, por otra parte, la otra cara de ese poder creativo es una impotencia específica del sujeto hablante frente a los juegos de lenguaje en que ha crecido, a los que ha sido «arrojado», diría Heidegger. En palabras de Wittgenstein, no se pueden modificar los «juegos del lenguaje» sin antes haber crecido en ellos: «la 'gramática' de los juegos de lenguaje ha de convertirse en ingrediente de la estructura de la personalidad. La experiencia retórica nos muestra un entrelazamiento de lenguaje y praxis». El lenguaje y la acción se interpretan recíprocamente: éste es el contenido del concepto wittgensteiniano de juego de lenguaje que a la vez es una forma de vida.

Habermas resume así la función de la hermenéutica y su limitada capacidad crítica:

La hermenéutica filosófica desarrolla, pues, y aquí no puedo hacer otra cosa que limitarme a señalarlo, las enseñanzas que acerca de la estructura de los lenguajes naturales podemos obtener de un uso reflexivo de la competencia comunicativa: la reflexividad y la objetividad son rasgos fundamentales del lenguaje al igual que la creatividad y la integración del lenguaje en la práctica de la vida. Tal saber reflexivo, que se resume en la 'conciencia hermenéutica', se distingue a todas luces de la habilidad misma de hacer un uso disciplinado de la comprensión y del discurso (Habermas 2007, p. 281).

Según la teoría de la «fusión de horizontes», a la comprensión del historiador le ha tomado ya siempre la delantera un contexto de tradición que determina la situación hermenéutica de partida y, por tanto, su comprensión. Y precisamente por ello, a través de la comprensión histórica se efectúa a la vez la prosecución de la tradición que el historiador hace suya.

Sin embargo, a lo que Habermas apunta (cuando afirma que la conciencia hermenéutica nada tiene que ver con la «habilidad misma de hacer un uso disciplinado de la comprensión y del discurso») es a que la prosecución de la tradición permanece acrítica: no podríamos, según Gadamer, trascender la tradición con la ilusoria intención de proseguir selectivamente determinados planteamientos contenidos en esa tradición y excluir otros. Y es que para Gadamer «la razón no está presente ni disponible cada vez que quiere ser consciente de sí misma, es decir, cada vez que quiere ser consciente de la racionalidad de algo (...). Su autoposibilitación está siempre referida a algo que no le pertenece a ella misma, sino que le acaece y, en esa medida, ella es sólo respuesta, como aquellas otras fueron respuestas míticas» (Gadamer 1999, 20 y s.). La razón depende de la experiencia previa, filtrada por la cultura, es decir, por la socialización en una tradición, dependiente ésta a su vez del texto clásico sobre el que se superponen continuas reinterpretaciones sociales, etc. En ese sentido, al tener que dirigir al mismo tiempo la mirada al texto y a la cosa que en él se trata, el intérprete está obligado a «entenderse en la cosa» 
antes de poder «recoger y entender la opinión del otro como tal» (Gadamer 1977, p. 363). El acontecer anónimo en que la tradición consiste cobraría así un núcleo de validez (donde yace la relevancia filosófica del prejuicio) que antecede a toda reflexión; y obtendría su fuerza vinculante de las operaciones interpretativas de los nacidos después y sobre todo de la fuerza espiritual de obras que se afirmen en su rango de «clásicas» por haber «resistido la prueba de la crítica histórica» (Gadamer 1977, p. 356). Por eso se puede afirmar que solamente aprendemos positivamente de las tradiciones, quedando descartada la viabilidad de toda crítica en el sentido emancipador pretendido por la Ilustración. Habermas lo resume así: nos movemos toda la vida en diálogos con textos y con cabezas que a través de largas distancias históricas siguen siendo nuestros contemporáneos (Habermas 2001, p. 45).

Pero, como enseguida veremos, para Habermas este aprendizaje, deudor de lo acaecido, al igual que el que brindaba la filosofía de la Historia o el historicismo, sigue siendo incorrecto por ciego o acrítico: de la Historia sólo se aprenderá negativamente, por algo así como lo que Kierkegaard llamara la «conciencia de pecado»:

Nuestra identidad no es solamente algo con que nos hayamos encontrado ahí, sino algo que es también y a la vez nuestro propio proyecto. Es cierto que no podemos buscarnos nuestras propias tradiciones, pero sí que debemos saber que está en nuestra mano el decidir cómo podemos proseguirlas. Gadamer piensa en este aspecto en términos excesivamente conservadores. Pues toda prosecución es selectiva, y es precisamente esta selectividad la que ha de pasar hoy a través del filtro de la crítica, de una apropiación consciente de la propia historia o (...) por el filtro de la 'conciencia de pecado'(Habermas 1989, p. 121). ${ }^{5}$

\section{LA UNIDAD DE LA RAZÓN COMUNICATIVA CONTRA LAS «CONTINUIDADES HISTÓ- RICAS»: LA HERMENÉUTICA «PROFUNDA» O «CRÍTICAMENTE ILUSTRADA» ${ }^{6}$ COMO CRÍTICA DE LA HERMENÉUTICA}

Hemos visto que con la reflexión hermenéutica se problematiza la apropiación (lingüística) de las tradiciones que compartimos intersubjetivamente y sin las cuales no podría operar nuestra razón, que ya las ha hecho suyas. La reflexión implica que el sujeto se torna consciente de los presupuestos inconscientes de sus operaciones, efectuadas hasta entonces intentione recta, es decir

5 El filtro crítico de la «conciencia de pecado» es algo que Habermas parece tomar de Kierkegaard: «pero éticamente sólo se elige uno a sí mismo arrepintiéndose, y sólo arrepintiéndose se torna uno concreto» (Habermas 1989, p. 99).

6 (Habermas 2007, p. 302). Sobre el concepto de hermenéutica crítica: (Conill Sancho 2006). 
efectuadas a partir de una entrega «natural» o efectiva al lenguaje abridor del mundo, desde una vivencia más que de un pensamiento. Una vez más: con la reflexión hermenéutica, quien está ya siempre arrojado a un lenguaje, toma conciencia de sus «peculiares libertades y dependencias respecto del lenguaje» (Habermas 2007, p. 281 y s.). Pero así sólo se clarifican las experiencias que el sujeto hablante hace en el uso de su competencia comunicativa, sin poder sin embargo explicar esa competencia. Al proceder siempre ad hoc («la universalidad de la experiencia hermenéutica se acopla magníficamente a la limitación real de toda experiencia humana y a las limitaciones impuestas a nuestra comunicación y nuestras posibilidades de articulación» (Gadamer 1997, p. 75)), no puede constituir un método científico. Y en ese sentido, Gadamer contrapone «método» a «verdad». En otras palabras, la hermenéutica se basaría en la idea de que la verdad depende absolutamente de la praxis de la comprensión y por eso se acaba definiendo a sí misma como el arte de la comprensión; así prescinde por completo de un método (que desde Descartes y para las ciencias modernas se identifica con una vía de confirmación) al cual, según él, la filosofía, convertida desde entonces en hacedora de sistemas e intermediaria entre la tradición metafísica y la ciencia moderna, nunca se debiera haber prestado (1997 p. 15). Todo método o marco es deudor de interpretaciones que confeccionan las verdades sociales: «el progreso de la ciencia y su aplicación racional a la vida social no creará una situación tan radicalmente distinta que no sea necesaria ya la 'amistad', es decir, una solidaridad sustentadora que por sí misma haga posible una ordenación del convivir humano». O sea que la arquitectónica de conocimientos que levanta ante nosotros el método científico, que queda disponible para el uso monológico (no dependiente de la praxis hermenéutica) del científico, no puede dejar de quedar «anclado de nuevo en la comunidad comunicativa en la que nos hallamos como personas» (p. 185). «Debemos recordar a los teóricos de este racionalismo crítico - dice Gadamer-, tanto como a los partidarios de enfoques lógicos a analíticos del lenguaje y teóricos del lenguaje en general, que su procedimiento racional, y más aún el aparato metodológico que están elaborando, y que van precisando más y más, únicamente es capaz de ejercer una función segundaria y que ni siquiera ayuda a plantear las preguntas que nos conmueven en tanto seres humanos mortales, portadores de cultura, representantes de tradiciones, mucho menos permite poner en duda la legitimidad de estas preguntas, o acaso eliminarlas o reducirlas»(p. 192).

Se atisba enseguida una peligrosa, por ciega, deriva normativa: «la filosofía práctica no consiste en la aplicación de la teoría a la práctica [...] sino que surge de la experiencia práctica misma gracias a lo que en ella hay de razón y de razonable. Y es que praxis no significa actuar según determinadas reglas o aplicar conocimientos, sino que se refiere a la situacionalidad más original del 
ser humano en su entorno natural y social» $(1997,183)$. La deuda impagable con esa «situacionalidad original» dibuja una ética conservadora que difícill mente habilita para la disposición crítica y que descansará inevitablemente en la reproducción de identidades colectivas gruesas, sobre fondos metafísicos de inteligibilidad (Taylor 1994, p. 72). Que la experiencia hermenéutica con el otro dé lugar a continuas fusiones de horizontes y que éstas, por definición, contribuyan a la reubicación de los fondos metafísicos sobres los cuales tejemos y destejemos identidades colectivas e individuales (y nuestras respectivas concepciones del bien), no significa que dicha evolución implique un aprendizaje asentado o un progreso moral.

Frente a ello, y negándose durante toda su obra a asumir que la reproducción social deba seguir una deriva ciega, ${ }^{7}$ Habermas se plantea si puede haber una teoría adecuada a la estructura de los lenguajes naturales que pueda servir de base a una comprensión metódicamente asegurada. Para reflexionar correctamente acerca de la conciencia hermenéutica, Habermas recurrió, en su texto titulado La pretensión de universalidad de la hermenéutica, de 1970, a la gnoseología genética de Piaget (Habermas 2007, p. 277). A partir de ella, Habermas vio indicios de que los seres humanos poseemos una inteligencia operativa prelingüística (independiente del lenguaje), compuesta por intereses u orientaciones (como el interés emancipador, que se encontraría trascendentalmente detrás de la acción comunicativa), por categorías (como espacio, tiempo, causalidad y sustancia) y por reglas de conexión lógica de los símbolos, que conformaría una condición previa necesaria para poder servirse del lenguaje, el cual se «asentaría» sobre ellas.

Por oposición a Gadamer, Habermas concluye en ese texto que los sistemas lingüísticos de la ciencia y de la elección racional de los que nos servimos estratégica y, por tanto, monológicamente, ponen un límite a la pretensión de universalidad de la hermenéutica. Los cálculos construidos monológicamente no pueden interpretarse sin referencia a un lenguaje natural, pero si «entenderse» prescindiendo de la problemática propia de la hermenéutica. Jesús Conill nos aclara que esto lleva a Habermas a concluir que «las condiciones del comprender no serían a la vez las condiciones de comunicación lingüística corriente» (Conill Sancho 2006, p. 198), como daba por hecho Gadamer. Si las

7 «Desde [la perspectiva de Habermas], la teoría social debe proceder a identificar en las estructuras normativas de las sociedades (y, en particular, en las prácticas políticas), partículas y fragmentos ya encarnados de una 'razón existente', para luego poder reconstruirlos reflexivamente con el objeto de que resulte factible remitirse a ellos como potencial emancipador. Encontrar tales asideros resulta crucial dado que hoy sólo cabe concebir el inconcluso proyecto normativo de la modernidad, como subraya una y otra vez el filósofo alemán, como un proyecto postmetafísico y secularizado, desprovisto además de cualesquiera garantías que una concepción metahistórica pudiera aportar» (Velasco Arroyo 2000, p. 10). 
primeras son necesariamente intersubjetivas, en las segundas sí cabe, y tiene relevancia, la estrategia monológica. Esto finalmente conduce a poner en tela de juicio la tesis hermenéutico-gadameriana fundamental de que «no podemos trascender el diálogo que somos», tesis que en el fondo sólo alberga inmovilismo.

«¿En qué estriba entonces el significado de la conciencia hermenéutica?», se pregunta. Esto, a su vez, le lleva a plantearse en otros términos la cuestión por la validez de la pretensión de universalidad de la hermenéutica: «¿es posible en relación con los propios plexos de símbolos del lenguaje ordinario una comprensión que no esté ligada a los presupuestos hermenéuticos de los procesos de comprensión dependientes del contexto y que en este sentido rebase el lenguaje natural como último metalenguaje?» Parece que sí.

Como decíamos, la hermenéutica gadameriana revela una peligrosa deriva ontologizadora, secundada hoy por diversas corrientes comunitaristas que priorizan la perspectiva del narrador sobre la perspectiva del participante, adoptando una noción culturalista del mundo de la vida (Habermas 2010, pp. 129 y ss. y 176). Al reducir la acción comunicativa al aspecto del entendimiento, identificando las condiciones del comprender con las condiciones de la comunicación lingüística corriente, la hermeneutización gadameriana de la transmisión lingüística no concibe la acción estratégica y acaba hipostasiando el mundo de la vida, tapándose los ojos ante los sesgos cognitivos o cargas del juicio, y neutralizando toda posibilidad de crítica. Se centra exclusivamente en la interpretación del lenguaje como algo último y objetivo, determinando en exceso a las personas que lo usan como su medio de transmisión (con ello, por cierto, también el concepto de tradición queda artificialmente objetivado desde la perspectiva de un observador), lo cual sólo puede abocar en el bloqueo del verdadero diálogo libre y abierto. No dista en la práctica de pregonar la inconmensurabilidad entre diferentes mundos de la vida o bagajes culturales. La consecuencia es que se ponen en primera línea la recepción cultural a partir de los textos denominados clásicos (desde el romanticismo los «clásicos» serán los así considerados por una comunidad -o por su establishment-), y se acaba priorizando la autoridad de éstos (de un pasado esencializado y comprendido en términos continuistas) frente a la razón. Y toda aclaración del malentendido pasaría por referirse a un consenso establecido de antemano por tradiciones convergentes (estamos obligados a referirnos a las precomprensiones concretas en que nos hemos socializado). Si se puede hacer crítica es siempre desde dentro de la socialización y toda otra tentativa de crítica será una sospecha abstracta que caería en una falsa conciencia.

Frente a este tipo de ideas, que han servido de sustento teórico a nacionalismos varios, Habermas advierte de dos cosas que la hermenéutica parece ignorar, más o menos interesadamente: por una parte incide en la relatividad de las propias culturas, de su falta de coherencia, homogeneidad y continuidad; 
y, por otra parte, recuerda la tesis más general de la teoría de sistemas, advirtiendo que existen lógicas estratégicas pensables más allá del lenguaje natural (es el caso de los imperativos sistémicos que funcionan según su propia lógica; como el mercado, sometido a la lógica del capital, que tiende a acumularse).

Consecuentemente, aunque nuestro autor también asuma que la acción comunicativa parte del mundo de la vida donde nos socializamos, no le otorga el mismo peso ontologizante sino que lo comprende como referente para la construcción social de la realidad: no cree que éste nos condene a una comprensión diferente, sino precisamente a una comprensión mejor. Apoyándose en la «experiencia hermenéutica del límite» (manifestaciones vitales difícilmente inteligibles), asume las dificultades de interpretación debidas a la distancia cultural, temporal o social. Y entiende que para la comprensión habrá que empezar descifrando un alfabeto, familiarizándonos con un léxico o averiguando reglas de aplicación específicas del contexto. Pero, contra Gadamer, él advierte que donde la conciencia hermenéutica se revelará siempre insuficiente no es en las comunicaciones interculturales, sino en los casos de «comunicación sistemáticamente distorsionada». Y esta distorsión, desde luego, también comprende a los textos de referencia que el nacionalismo sabe manipular como nadie (Alonso 2014).

Es por eso que, en lugar de centrarse en el texto, Habermas pone en primera línea al sujeto cognoscente, al intérprete del texto (a su reflexión crítica, en realidad), que pasa a ser no sólo traductor, sino también transformador. Está claro que con esto Habermas trata de mantener abierta una vía crítica. Ello es porque sabe bien que la transmisión de una tradición está marcada por reinterpretaciones y discontinuidades, analizables desde una perspectiva histórico-social concreta de manipulación: «a conversación que somos» no es precisamente diáfana sino que en su interior esconde facticidades como la violencia, las coacciones y las estrategias. «Todo consenso en que la comprensión termina queda en principio bajo sospecha de haber sido impuesto pseudocomunicativamente» y la tarea ilustrada consiste en revelar el plexo de poder que lo estaría forzando para favorecer la verdadera comunicación. ${ }^{8} \mathrm{Y}$ es que la retórica como arte de producir consenso en cuestiones que no pueden decidirse con argumentos concluyentes esconde «el momento de violencia que hasta el día de hoy no ha podido eliminarse de los procesos de formación de la voluntad colectiva».

8 «La pretensión de universalidad del enfoque hermenéutico sólo puede mantenerse si se parte de que la tradición como lugar de verdad posible y de acuerdo fáctico es también el lugar de la no-verdad fáctica y de la perpetuación del poder» [Wellmer, Kritische Gesellschaftstheorie und Positivismus, Franckfurt, 1969, pp. 48 y ss. (en Habermas 2007, p. 301 y s.)]. 
Consecuentemente, la «hermenéutica profunda» que propone Habermasen realidad prolonga la reflexión hermenéutica: ${ }^{9}$ se trata de un saber metahermenéutico acerca de las condiciones de posibilidad de la comunicación sistemáticamente distorsionada que «se extiende a las formas de intersubjetividad del lenguaje y al nacimiento de sus deformaciones» (Habermas 2007, p. 299; 2008a, p. 42). Su propuesta teórica entronizará la unidad de la razón comunicativa en la multiplicidad de sus voces (Habermas 1988b) y pasará por reconstruir trascendentalmente los presupuestos pragmáticos universales de la comunicación (Habermas 2008b), que constituyen nuestra inteligencia operativa prelingüística, y que servirán de referencia para desenredar las coacciones y violencias fácticas que distorsionan sistemáticamente la comunicación, incluso dentro de la misma cultura; la cual, por lo tanto, puede ser incorrectamente transmitida e interiorizada. Cuando caigamos en la cuenta de las violencias que esconde la transmisión consensuada de la tradición será cuando aprendamos, negativamente (como no puede ser de otra forma), de la historia.

Huelga decir que Auschwitz conforma el paradigma de aprendizaje negativo de la historia; representa una 'ruptura civilizacional' que sirvió a Occidente, y sobre todo a Alemania, para abandonar las tradiciones asentadas en el nacionalismo étnico (que los alemanes arrastraban desde Bismarck) y abrazar una identidad colectiva postconvencional, de corte universalista (incluyente y no excluyente), como el «patriotismo constitucional». En Auschwitz quedó rota la capa de solidaridad con todo lo que lleva rostro humano: la «ingenuidad de la que habían extraído su autoridad tradiciones incuestionadas, de las que se habían nutrido continuidades históricas», queda rota. "Auschwitz cambió las condiciones relativas a la continuación de la vida histórica» (Habermas 1989, p. 87). Trata así Habermas de poner fin a la opaca tesis neoaristotélica de que una tradición sólo puede enjuiciarse desde sí misma, ya que «esto sólo es plausible si pudiéramos confiar en que a las prácticas les basta para acreditarse el venir sustentadas por la solidez de una tradición»; pero las cámaras de gas han roto la «confianza antropológica» en la que dicha tesis se sustentaba. «Desde entonces ya no es posible una vida consciente sin desconfiar de toda continuidad que se afirme incuestionadamente y que pretenda también extraer su propia validez de ese su carácter incuestionado»(1989, p. 114).

9 La crítica «permanece ligada al plexo de tradición sobre el que reflexiona. La objeción hermenéutica de Gadamer está en lo cierto frente a todas las autocertezas que osara atribuirse una crítica que procediese monológicamente. Pues la interpretación hecha en términos de hermenéutica profunda no puede tener otra confirmación que la autorreflexión efectiva de todos los participantes lograda en el diálogo» (Habermas 2007, pp. 305-306) Sobre esto, también:(Conill Sancho 2006, p. 198). 
En resumen, Habermas retoma la tesis hermenéutica esencial según la cual sólo gracias al «lenguaje abridor del mundo», del que hablaba Heidegger, dos sujetos con dos bagajes culturales distintos podrían ir poco a poco comprendiendo lo que quiere decir el otro, hasta entenderse. Pero añade que sólo gracias a un entendimiento libre de coacciones podríamos liberarnos de las cadenas que nos impone la tradición. Un entendimiento que, para quedar libre de coacciones (o para que al menos seamos reflexivamente conscientes de dichas coacciones como primer paso hacia la libertad), requerirá desvelar (y regular -por eso el Derecho cobrará protagonismo en su Teoría de la acción comunicativa y, sobre todo, en Facticidad y validez, donde adquiere una función legitimadora en su un papel de bisagra entre el ámbito de la sociedad civil y los sistemas institucionalizados-) la lógica de los imperativos sistémicos (poder y dinero) que atraviesan y distorsionan constantemente la comunicación.

\section{REFERENCIAS BIBLIOGRÁFICAS:}

ALONSO, M. 2014: El catalanismo, del éxito al éxtasis I: la génesis de un problema social. España: El Viejo Topo

CONILL, J. 2006: Ética hermeneútica: Crítica desde la facticidad. Madrid: Tecnos.

DALLMAYR, F. 2006: «Globalization and inequality: A plea for cosmopolitan justice». Comparative Studes of South Asia, Africa and the Middel East 26 (1): 3-14.

____ 2001. «Ethics and international politics: A response». Journal of International Political Theory 7 (2): 252-63.

GADAMER, H. G. 1999: Mito y razón. Barcelona etc.: Paidós.

, 1997: El giro hermenéutico. Madrid: Cátedra.

, 1977: Verdad y método. Salamanca: Sígueme.

HABERMAS, J. 2010: Teoría de la acción comunicativa. Madrid: Trotta.

____ 2008b «Acción comunicativa y razón sin trascendencia», Entre Naturalismo y Religión, pp. 31-82. Barcelona etc.: Paidós.

____ 2008a: Conciencia moral y acción comunicativa. Madrid: Trotta.

___ 2007: La lógica de las ciencias sociales. Madrid: Tecnos.

___ 2001: Más allá del estado nacional. Madrid: Trotta.

___ 1989: Identidades nacionales y postnacionales. Madrid: Tecnos

1988a: «Individuación por vía de socialización. Sobre la teoría de la subjetividad de George Herbert Mead», Pensamiento postmetafísico, pp. 138239. Madrid: Tecnos 
___ _ 1988b: «La unidad de la razón comunicativa desde la multiplicidad de sus voces», Pensamiento postmetafísico, pp. 138-239. Madrid: Tecnos

SIURANA, J. C. 2003: Una brújula para la vida moral. la idea de sujeto en la ética del discurso de karl-otto apel. Granada: Comares.

TAYLOR, C. 1994: La ética de la autenticidad. Barcelona etc.: Paidós.

VELASCO ARROYO, J. C. 2000: La teoría discursiva del derecho: Sistema jurídico y democracia en habermas. Madrid: Centro de estudios sociales y constitucionales.

Mikel Arteta es Doctor en Filosofía moral y política por la Universidad de Valencia

Líneas de investigación:

Filosofía contemporánea.

Publicaciones:

-Arteta, Mikel. 2013: «Hacia la constitucionalización cosmopolita: la propuesta de Jürgen Habermas», Bioética, Neuroética, Libertad y Justicia, Granada: Comares (ISBN: 978-84-9045-073-4)

-Arteta, Mikel. 2014: «Contra las dos patas del secesionismo». Claves de Razón Práctica n 234 (may-jun 2014), pp. 70-79.

Correo electrónico: mikel.arteta@uv.es 
